\title{
Creation of a Natural Health Products Database for Assessing Safety for Patients with Chronic Kidney Disease or Renal Transplant
}

\author{
Sharon Leung, Karen Shalansky, Puneet Vashisht, Marianna Leung, and Judith G Marin
}

\begin{abstract}
Introduction: There is a lack of published safety information on the use of natural health products (NHPs) for patients with chronic kidney disease (CKD) or renal transplant.

Objective: To create an online database to provide evidence-based safety recommendations for commonly used NHPs, specific to patients with CKD or renal transplant.
\end{abstract}

Methods: NHPs used by CKD and transplant patients in British Columbia were identified from the records of the BC Provincial Renal Agency. For each NHP, several databases (MEDLINE, Embase, LexiNatural Products, PubMed Dietary Supplement Subset, and Natural Medicines) were searched for any information pertaining to dosage, adverse drug reactions, drug interactions, immunomodulatory effects, and pharmacokinetics in patients with renal disease. Each NHP was given 1 of 4 safety ratings: likely safe, possibly safe, possibly unsafe, and likely unsafe. An NHP was classified as "possibly unsafe" for patients with renal transplant if it had demonstrated in vitro immunomodulatory effects and/or significant interactions with transplant medications due to effects on the cytochrome P450 3A4 isozyme.

Results: Of the 19627 BC-registered patients with renal disease (as of August 2014), 4122 (21\%) were using one or more NHPs. The HerbalCKD website (www.herbalckd.com) was created in 2015 to provide information about 47 commonly used NHPs and 2 known nephrotoxins (aristolochic acid and silver). This website provides a systematic evaluation of safety information for selected NHPs for patients with CKD (both nondialysis and dialysis-dependent) and kidney transplant. The most common NHP safety classification was "possibly safe", reflecting the paucity of studies in renal populations and the availability of safety data for the general population. Limitations of the website include difficulty in interpreting and generalizing the safety literature because most NHP formulations are not standardized, and others are combination products.

Conclusion: The website www.herbalckd.com provides an easy-to-use, evidence-based tool for health care professionals to assess the safety of NHPs for CKD and transplant patients.

Keywords: herbal products, natural health products, chronic kidney disease, transplantation, dialysis

Can J Hosp Pharm. 2017;70(5):343-8

\section{RÉSUMÉ}

Contexte : On observe qu'il n'existe que très peu d'information publiée sur l'innocuité des produits de santé naturels (PSN) pour les patients souffrant d'insuffisance rénale chronique ou ayant subi une greffe rénale. Objectif : Créer une base de données en ligne qui sert à fournir des recommandations de sécurité fondées sur des données probantes au sujet des PSN les plus employés spécifiquement à l'intention des patients atteints d'insuffisance rénale chronique ou ayant subi une greffe rénale.

Méthodes : Les PSN utilisés par les patients souffrant d'insuffisance rénale chronique ou ayant subi une greffe rénale ont été répertoriés d'après les dossiers de la BC Provincial Renal Agency. Pour chaque PSN, plusieurs bases de données (MEDLINE, Embase, Lexi-Natural Products, PubMed Dietary Supplement Subset et Natural Medicines) ont été interrogées afin d'y chercher des informations sur la posologie, les réactions indésirables aux médicaments, les interactions médicamenteuses, les effets immunomodulateurs et la pharmacocinétique chez les patients atteints d'insuffisance rénale. Chaque PSN s'est vu attribuer l'un de quatre degrés de sécurité : probablement sécuritaire, possiblement sécuritaire, possiblement nocif et probablement nocif. Un PSN était classé " possiblement nocif " pour les patients ayant subi une greffe rénale s'il a manifesté in vitro des effets immunomodulateurs ou des interactions importantes avec les médicaments antirejet à cause de l'isozyme 3A4 du cytochrome P450.

Résultats : Parmi les 19627 patients insuffisants rénaux inscrits en Colombie-Britannique, 4122 (21\%) utilisaient au moins un PSN (en date d'août 2014). Le site Web HerbalCKD (www.herbalckd.com) a été créé en 2015 afin de fournir de l'information sur 47 des PSN les plus utilisés et sur deux néphrotoxines connues (l'acide aristolochique et l'argent). Ce site Web offre une évaluation systématique des informations sur l'innocuité de PSN choisis qui pourraient être utilisés par les patients souffrant d'insuffisance rénale chronique (dialysés ou non) ou ayant subi une greffe rénale. Les PSN étaient le plus souvent classés sous " possiblement sécuritaire ", ce qui souligne le peu d'études auprès des populations souffrant de troubles rénaux et la disponibilité de données sur l'innocuité dans la population générale. Parmi les limites du site Web, on compte la difficulté à interpréter et à généraliser la littérature sur l'innocuité parce que la plupart des formules de PSN ne sont pas normalisées et que certains PSN sont un mélange de substances.

Conclusion : Le site Web www.herbalckd.com représente pour les professionnels de la santé un outil simple et fondé sur des données probantes leur permettant d'évaluer l'innocuité de PSN pour les patients atteints d'insuffisance rénale chronique ou ayant subi une greffe rénale.

Mots clés : plantes médicinales, produits de santé naturels, insuffisance rénale chronique, greffe, dialyse 


\section{INTRODUCTION}

recent market research survey showed that $73 \%$ of A Canadians regularly take a natural health product (NHP). ${ }^{1}$ Health Canada defines NHPs as vitamins, minerals, herbal remedies, homeopathic medicines, traditional medicines (e.g., traditional Chinese medicines), probiotics, and other products (e.g., amino acids, essential fatty acids) that are available over the counter without a prescription. ${ }^{1}$ There is a common belief among consumers that NHPs are safe to use because they are "natural". ${ }^{2}$ However, there exists a gap in the literature regarding safety data for NHPs, especially for patients with chronic kidney disease (CKD) or renal transplant. Safety concerns associated with NHP use in the general population most commonly arise because of lack of standardization of the products, which can have varying and sometimes unknown content. ${ }^{2}$ Additional concerns about use of NHPs by patients with CKD or renal transplant include interactions between NHPs and prescription medications (e.g., anti-rejection medication), altered pharmacokinetics in patients with reduced renal function, potential for nephrotoxicity or immunomodulation, and limited information about their dialyzability. $^{3}$

The objectives of this project were to determine the NHPs commonly used by British Columbia residents with CKD (both nondialysis [CKD-ND] and dialysis-dependent) and those with kidney transplant, and their patterns of use; to collate and analyze literature on the safety, drug interactions, immunomodulating activity, and pharmacokinetic profiles of these products; and to create an online database providing evidence-based recommendations for health care professionals regarding NHP use in patients with kidney disease and transplant.

\section{METHODS}

\section{Determination of NHP Usage}

In British Columbia, services for CKD and kidney transplant patients are coordinated by the BC Provincial Renal Agency (BCPRA). Each patient's clinical information, including medication regimen, is collected and entered into the agency's Patient Records and Outcome Management Information System (PROMIS). The number of NHP entries for CKD-ND, dialysis, and renal transplant patients was obtained from this database, using data derived from entries listed on August 1, 2014. Vitamins were excluded, because they were to be evaluated in a second phase. Calcium supplements were also excluded, because they are primarily used as phosphate binders in the renal population. Nutritional supplements and herbal teas were excluded, because these items are not entered into PROMIS. Input was solicited from other renal pharmacists across Canada to identify NHPs commonly used in other renal practices, in addition to the ones identified through the PROMIS database. The demographic characteristics of NHP users and non-users (e.g., age, sex, ethnic background) were also determined from the PROMIS database.
Statistical tests, specifically $t$ tests and $\chi^{2}$ tests, were performed to compare the demographic characteristics of NHP users and non-users. Access to the PROMIS database was approved by the Research Committee of the BCPRA.

\section{Literature Search and Data Collation}

The following databases were searched: MEDLINE, Embase, Lexi-Natural Products, PubMed Dietary Supplement Subset, and Natural Medicines (formally known as the Natural Standard and Natural Medicines Comprehensive Database). Keywords for the search were the specific name of each NHP (as "common name" OR "scientific name"), "chronic renal failure" OR "chronic kidney failure" OR "renal insufficiency", "hemodialysis", "peritoneal dialysis", "kidney graft" OR "renal transplant", "immunomodulating" OR "immunology" OR “immunomodulation", "pharmacokinetics", "nephrotoxicity", "CYP450", "cyclosporine" OR "tacrolimus", "mycophenolate", "warfarin". There were no restrictions on the search strategy with the exception of citations that did not pertain to patients with renal disease. Authors of pertinent papers were contacted if information was incomplete (e.g., if only an abstract was available online). References of pertinent articles were also hand-searched for additional studies.

For each NHP, information in the literature pertaining to renal dosage adjustment, adverse drug reactions, drug interactions, immunomodulating effects, and pharmacokinetics (to determine dialyzability; specifically molecular weight, volume of distribution, protein binding, renal elimination) was recorded. The specific dose used in trials enrolling CKD-ND, dialysis (hemodialysis or peritoneal dialysis), and renal transplant patients was also documented, if available. Adverse drug reaction data for NHPs were separated into common and nephrotoxic effects; commonly reported reactions were determined from trials involving both non-renal and renal patient populations, if available. Regarding drug interactions, only common interactions, with specific focus on immunomodulation and increased bleeding risk, and effects on the cytochrome P450 metabolic system were documented. Human studies, case series, and reports pertinent to renal disease and transplant were systematically summarized with respect to safety outcomes. Because the purpose of the new online database was to present information about the safety of NHPs, literature about their efficacy was not evaluated. For each NHP, one of the nephrology-trained investigators (S.L., K.S., M.L., J.G.M.) independently performed a literature search, critically reviewed the literature, and finalized the monograph. Discrepancies or questions that arose through the literature review were discussed, and consensus was reached among the authors.

\section{Safety Rating System}

NHPs were classified into safety rating categories based on those in the Natural Medicines database, ${ }^{4}$ with modifications 
based on safety specifically in the renal population, if available (Table 1). On the website for the new database, the safety ratings are colour-coded as follows: green $=$ likely safe, blue = possibly safe, orange $=$ possibly unsafe, and red $=$ unsafe. A more cautious approach was undertaken in determining safety ratings for the transplant population, whereby an NHP was categorized as possibly unsafe if it had in vitro immunomodulatory effects and/or significant interactions involving the CYP3A4 isozyme.

\section{RESULTS}

The PROMIS database had a total of 3433 entries for 48 NHPs. Some of the NHPs listed were duplicates and were thus combined: ubidecarenone with coenzyme Q10, $\alpha$-linolenic acid with flaxseed, and chromium picolinate with chromium. NHPs that were omega-3 fatty acids were separated according to Natural Standards categorization ${ }^{4}$; thus, cod liver oil, krill oil, and flaxseed were kept as separate entities, whereas halibut oil, salmon oil, omega-3 fatty acid, and omega-3-6-9 fatty acid complex were combined as "fish oils". Lactobacillus and Saccharomyces were kept as separate entities, along with a broader category of "probiotics". This left 38 distinct NHPs, 2 combination products (glucosamine + chondroitin, Strauss Heartdrops), and 2 broad categories (fish oil, probiotics) (Table 2). From this list, 31 NHPs were chosen at random by one of the authors for initial work-up and analysis, along with another 18 NHPs that were identified by renal pharmacists; the final list of 49 products included 2 known nephrotoxins (aristolochic acid, silver).
NHP users represented 21.0\% (4122/19 627) of the renal patients registered in PROMIS. The proportions of NHP users per renal group were $22.3 \%$ (2833/12 699) for CKD-ND, $20.0 \%$ (580/2903) for dialysis, and 17.6\% (709/4025) for transplant. Compared with non-users, NHP users were significantly older (mean \pm standard deviation $69.8 \pm 14.5$ years versus $67.2 \pm 17.2$ years, $p<0.001)$ and predominantly female $(51.0 \%$ [2102/4122] versus $43.8 \%$ [6791/15 505], $p<0.001)$. The majority of NHP users were white $(67.9 \%$ [2799/4122] $)$, as were more than half of the patients overall in the PROMIS registry $(55.0 \%$ [10 795/19 627]). People of Asian background represented 14.1\% $(581 / 4122)$ of NHP users and $20.6 \%(3194 / 15505)$ of non-users $(p<0.001)$.

The new online database, HerbalCKD (www.herbalckd. com), was created in 2015. Table 3 presents an alphabetized list of the 10 most common NHPs from the PROMIS database that were reviewed for the website and their safety ratings. A sample monograph from the website, for evening primrose oil, is presented in Appendix 1 (available at www.cjhp-online.ca/ index.php/cjhp/issue/view/123/showToc). Most of the NHPs were categorized as "possibly safe" for all 3 populations of interest, with only 2 drugs (aristolochic acid, silver) categorized as unsafe for all 3 groups. The transplant group had more NHPs categorized as "possibly unsafe" than the other 2 groups because of potential immunomodulating effects and/or significant CYP3A4-mediated interactions with transplant medications.

Table 1. Definitions in the Safety Rating System Used at the HerbalCKD Website*

\begin{tabular}{ll} 
Safety Ratingt & \multicolumn{1}{c}{ Definition } \\
\hline Likely safe (green) & $\begin{array}{l}\text { Available evidence in a renal population measures and reports safety and adverse } \\
\text { outcomes data and consistently shows no significant serious adverse effects, } \\
\text { nephrotoxicity, immunomodulation, and/or drug interactions. In addition, the NHP } \\
\text { is also categorized as "likely safe" for the general population. }\end{array}$ \\
\hline Possibly safe (blue) & $\begin{array}{l}\text { Available evidence in a renal population measures and reports safety and adverse } \\
\text { outcomes data but has significant methodological flaws and shows no significant } \\
\text { serious adverse effects, nephrotoxicity, immunomodulation, and/or drug interactions. } \\
\text { In the absence of a study in the renal disease population, there is evidence showing } \\
\text { safety in the general population. Some contrary evidence may exist; however, } \\
\text { available evidence supporting safety outweighs contrary evidence. }\end{array}$ \\
\hline $\begin{array}{l}\text { Available evidence in a renal population measures and reports safety and adverse } \\
\text { outcomes data and shows adverse effects, nephrotoxicity, immunomodulation, and/or } \\
\text { drug interactions. Some evidence of safety may exist; however, available evidence } \\
\text { supporting potential negative concerns outweighs evidence of safety. In the absence } \\
\text { of a study in the renal population, there is evidence showing potential harm in the } \\
\text { general population. }\end{array}$ \\
$\begin{array}{l}\text { Available evidence in a renal population measures and reports safety and adverse } \\
\text { outcomes data and consistently shows significant serious adverse effects, } \\
\text { nephrotoxicity, immunomodulation, and/or drug interactions. In the absence of a } \\
\text { study in the renal population, there is evidence of definite harm in the general } \\
\text { population. }\end{array}$ \\
\hline Unsafe (red)
\end{tabular}

$\mathrm{NHP}=$ natural health product

*Based on the safety rating system of the Natural Medicines database ${ }^{4}$

tFor each NHP listed at the HerbalCKD website, 3 ratings are provided, one for each of the 3 target populations: patients with chronic kidney disease (dialysis-dependent or not receiving dialysis) and patients with kidney transplant. At the website, each rating appears in a circle with the relevant colour. 
This single copy is for your personal, non-commercial use only.

For permission to reprint multiple copies or to order presentation-ready copies for distribution, contact CHHP at publications@cshp.ca

Table 2. Entries for Natural Health Products in the Patient Records and Outcome Management Information System (PROMIS) of the BC Provincial Renal Agency

\begin{tabular}{|c|c|c|c|}
\hline Natural Health Product & $\begin{array}{l}\text { No. (\%) o } \\
\text { PROMIS }\end{array}$ & $\begin{array}{l}\text { Entries in } \\
?=3433 \text { ) }\end{array}$ & Comment \\
\hline Fish oil & 1544 & $(45.0)$ & $\begin{array}{l}\text { Includes halibut oil, salmon oil, omega-3 fatty acids, } \\
\text { omega-3-6-9 fatty acid complex }\end{array}$ \\
\hline Coenzyme Q10* & 343 & $(10.0)$ & = ubidecarenone \\
\hline Glucosamine* & 318 & $(9.3)$ & \\
\hline Probiotics & 157 & (4.6) & \\
\hline Melatonin* & 156 & (4.5) & \\
\hline Cranberry* & 138 & $(4.0)$ & \\
\hline Lutein* & 94 & $(2.7)$ & \\
\hline Garlic* & 93 & $(2.7)$ & \\
\hline Flaxseed* & 84 & (2.4) & $=\alpha$-linolenic acid; omega-3 fatty acid \\
\hline Zinc* & 82 & (2.4) & \\
\hline Glucosamine + chondroitin* & 64 & (1.9) & \\
\hline Lactobacillus acidophilus* & 61 & (1.8) & \\
\hline Saw palmetto* & 39 & $(1.1)$ & \\
\hline Lecithin* & 32 & $(0.9)$ & \\
\hline Cod liver oil & 32 & (0.9) & Omega-3 fatty acids \\
\hline Selenium* & 30 & (0.9) & \\
\hline Gingko biloba* & 22 & (0.6) & \\
\hline Chromium* & 18 & $(0.5)$ & Includes chromium picolinate \\
\hline Evening primrose oil* & 17 & $(0.5)$ & \\
\hline Grape seed extract* & 16 & (0.5) & \\
\hline Echinacea* & 16 & $(0.5)$ & \\
\hline Ginseng* & 16 & $(0.5)$ & \\
\hline Serrapeptase* & 10 & $(0.3)$ & \\
\hline Krill oil* & 7 & $(0.2)$ & \\
\hline Tryptophan* & 7 & $(0.2)$ & Omega-3 fatty acids \\
\hline Curcumin* & 6 & $(0.2)$ & Active ingredient in turmeric \\
\hline Saccharomyces boulardii* & 5 & $(0.1)$ & \\
\hline Phosphatidylserine & 4 & $(0.1)$ & \\
\hline Celadrin* & 3 & $(0.1)$ & \\
\hline Valerian* & 3 & $(0.1)$ & \\
\hline Glutathione & 2 & $(0.1)$ & \\
\hline Iberogast & 2 & $(0.1)$ & \\
\hline St John's wort* & 2 & $(0.1)$ & = Hypericum perforatum \\
\hline Arginine & 2 & $(0.1)$ & \\
\hline Strauss Heartdrops & 1 & $(<0.1)$ & \\
\hline Silica & 1 & $(<0.1)$ & \\
\hline Royal jelly* & 1 & $(<0.1)$ & \\
\hline Silver* & 1 & $(<0.1)$ & \\
\hline Shark cartilage* & 1 & $(<0.1)$ & \\
\hline$\alpha$-lipoic acid* & 1 & $(<0.1)$ & \\
\hline Copper & 1 & $(<0.1)$ & \\
\hline Boron & 1 & $(<0.1)$ & \\
\hline
\end{tabular}

*Reviewed and analyzed for HerbalCKD website.

\section{DISCUSSION}

We created an online database (www.herbalckd.com) to present our systematic evaluations of safety information on an initial 49 NHPs in 3 renal populations: CKD-ND, dialysis, and transplant. The website provides an easy-to-understand, colourcoded safety rating system, specific to renal populations. The most common NHP safety classification was "possibly safe", reflecting the paucity of studies in renal populations and the availability of safety data for the general population.
The rate of NHP usage by patients in the BCPRA database (21\%) generally fell below published prevalences of $29 \%-45 \%$ for CKD-ND patients, ${ }^{5-7} 18 \%-57 \%$ for patients receiving dialysis, ${ }^{8,9}$ and $49 \%-58 \%$ for patients with kidney transplant. ${ }^{8,10}$ Different definitions of NHPs, as well as inclusion in those studies of certain agents (such as vitamins, diet supplements, and herbal teas) that were excluded from the PROMIS database, could have contributed to these higher rates. In addition, NHP use was likely underreported in the current study. Although medication recon- 
This single copy is for your personal, non-commercial use only.

For permission to reprint multiple copies or to order presentation-ready copies for distribution, contact CJHP at publications@cshp.ca

\section{Table 3. Ten Commonly Used Natural Health Products and Their Safety Ratings, as Presented on the HerbalCKD Website}

\begin{tabular}{lccc} 
& \multicolumn{3}{c}{ Population; Safety Rating } \\
\cline { 2 - 4 } Natural Health Product & CKD-ND & HD/PD & Transplant \\
\hline Chondroitin sulphate & Possibly safe & Possibly safe & Possibly unsafe \\
Coenzyme Q10 & Likely safe & Likely safe & Possibly safe \\
Cranberry & Possibly safe & Possibly safe & Possibly safe \\
Flaxseed & Possibly safe & Possibly safe & Possibly safe \\
Garlic & Possibly safe & Possibly safe & Possibly safe \\
Glucosamine & Possibly safe & Possibly safe & Possibly unsafe \\
Lactobacillus sp. & Likely safe & Likely safe & Unsafe \\
Lutein & Possibly safe & Possibly safe & Possibly safe \\
Melatonin & Possibly safe & Likely safe & Possibly unsafe \\
Saw palmetto & Possibly safe & Possibly safe & Possibly unsafe \\
\hline
\end{tabular}

CKD-ND = chronic kidney disease, nondialysis; HD/PD = hemodialysis or peritoneal dialysis.

ciliation is routinely performed for all renal patients, it is uncertain whether individual health practitioners consistently question patients about NHP use. Studies have reported that $50 \%-87.5 \%$ of patients with renal disease do not discuss NHP consumption with their health care team, either because they are not asked about NHP use or because they fear disapproval. ${ }^{7,8}$ Furthermore, data entry for NHPs in the PROMIS database may be inconsistent among renal programs in different regions of the province, as not all programs have a pharmacist performing medication reconciliation.

Limitations to creation of the website included the limited availability of safety data for renal populations; furthermore, the NHP literature for the general population usually focuses on efficacy as opposed to safety. Additionally, some NHPs are combination products, which can confound product safety and the generalizability of safety information. Lastly, most NHP formulations are not standardized, which makes it difficult to compare studies using different formulations or to interpret information derived from a single case report.

\section{CONCLUSION}

As of August 2017, the website www.herbalckd.com contains safety information on 47 commonly used NHPs in the renal population and 2 known nephrotoxic NHPs (aristolochic acid, silver). The website provides an evidence-based, easy-to-use tool for health care professionals, allowing educated decisions on whether a particular NHP can be safely continued or not. The database is continuously being expanded with the addition of monographs for other NHPs, including vitamins. The safety rating system was based on that of the Natural Medicines database, ${ }^{4}$ with a focus on clinical trials specific to NHPs in populations with renal disease and kidney transplant.

\section{References}

1. Natural health products. Ottawa (ON): Health Canada; [updated 2015 May 1; cited 2016 May 11]. Available from: www.hc-sc.gc.ca/dhp-mps/ prodnatur/index-eng.php
2. Bent S. Herbal medicine in the United States: review of efficacy, safety, and regulation: grand rounds at University of California, San Francisco Medical Center. Gen Intern Med. 2008;23(6):854-9.

3. Dahl NV. Herbs and supplements in dialysis patients: panacea or poison? Semin Dial. 2001;14(3):186-92.

4. Natural medicines [database]. Stockton (CA): Therapeutic Research Center; [cited 2014 Sep - 2017 Jun]. Accessed through institutional subscription. Also available from: https://naturalmedicines.therapeuticresearch.com/; subscription required to access content.

5. Laliberté MC, Normandeau M, Lord A, Lamarre D, Cantin I, Berbiche D, et al. Use of over-the-counter medications and natural products in patients with moderate and severe chronic renal insufficiency. Am J Kidney Dis. 2007;49(2):245-56

6. Spanner ED, Duncan AM. Prevalence of dietary supplement use in adults with chronic renal insufficiency. J Ren Nutr. 2005;15(2):204-10.

7. Tangkiatkumjai M, Boardman H, Praditpornsilpa K, Walker DM. Prevalence of herbal and dietary supplement usage in Thai outpatients with chronic kidney disease: a cross-sectional survey. BMC Complement Altern Med. 2013;13:153-62.

8. Nowack R, Ballé C, Birnkammer F, Koch W, Sessler R, Birck R. Complementary and alternative medications consumed by renal patients in southern Germany. J Ren Nutr. 2009;19(3):211-9.

9. Kleshinski JF, Crews C, Fry E, Stewart B, Reinhart C, Tolliver J, et al. A survey of herbal product use in a dialysis population in northwest Ohio. J Ren Nutr. 2003;13(2):93-7.

10. Foroncewicz B, Mucha K, Gryszkiewicz J, Florczak M, Mulka M, Chmura A, et al. Dietary supplements and herbal preparations in renal and liver transplant recipients. Transplant Proc. 2011;43(8):2935-7.

Sharon Leung, BSc(Pharm), is a Clinical Pharmacist with St Paul's Hospital and a Providence Healthcare Experiential Education Facilitator with the Faculty of Pharmaceutical Sciences, The University of British Columbia, Vancouver, British Columbia.

Karen Shalansky, PharmD, FSCHP, is a Pharmacotherapeutic Specialist with Vancouver General Hospital and a Clinical Professor with the Faculty of Pharmaceutical Sciences, The University of British Columbia, Vancouver, British Columbia.

Puneet Vashisht, BSc(Pharm), was, at the time this study was performed, a fourth-year pharmacy student in the Faculty of Pharmaceutical Sciences, The University of British Columbia, Vancouver, British Columbia. He is now a Pharmacy Resident with Lower Mainland Pharmacy Services, Vancouver, British Columbia. 
Marianna Leung, PharmD, is a Clinical Pharmacy Specialist with St Paul's Hospital and a Clinical Assistant Professor with the Faculty of Pharmaceutical Sciences, The University of British Columbia, Vancouver, British Columbia.

Judith G Marin, MSc, PharmD, is a Clinical Pharmacy Specialist with St Paul's Hospital and a Clinical Assistant Professor with the Faculty of Pharmaceutical Sciences, The University of British Columbia, Vancouver, British Columbia.

Competing interests: None declared.

\section{Address correspondence to: \\ Dr Karen Shalansky \\ Pharmacy Department \\ Vancouver General Hospital \\ 855 West 12th Avenue \\ Vancouver BC V5Z 1M9 \\ e-mail: karen.shalansky@vch.ca \\ Funding: None received.}

Acknowledgements: The authors would like to acknowledge Matthew Morrison, Josh Batterink, Benjamin Wou, Selina Grewal, and Fiona Kwong for their assistance with data collection and creation of the website.

\section{BEST..is better}

\section{One resource for all types of compounding by pharmacies}

\section{WHAT'S INSIDE?}

- Information for pharmacists, pharmacy technicians, planners, architects, engineers-and others who are involved in decisions or activities that affect compounding

- Guidelines for aseptic compounding, non-aseptic compounding, and compounding which involves hazardous drugs-including radiopharmaceuticals

- Best and leading guidelines on topics such as training, planning and designing the physical environment, developing an air quality strategy, cleaning and decontaminating areas, monitoring the environment, garbing and hand hygiene, developing compounding procedures, documenting, and much more-all in only 230 pages

\section{Learn what best looks like: add this publication to your library!}

HAVE A SNEAK PEEK OR ORDER AT:

https://cshp.ca/compounding-guidelines-pharmacies CSHP MEMBERS PAY A DISCOUNTED PRICE
Canadian Society of Hospital Pharmacists

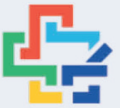

Société canadienne des pharmaciens d'hôpitaux 